\title{
LOGÍSTICA REVERSA ATRAVÉS DA ECONOMIA CRIATIVA E DO DESENVOLVIMENTO SUSTENTÁVEL
}

\author{
Priscilla Monge Brugeff ${ }^{1}$ \\ Heitor Romero Marques ${ }^{2}$ \\ Reginaldo Brito da Costa ${ }^{3}$ \\ Pedro Pereira Borges ${ }^{4}$
}

\section{INTRODUÇÃO}

O processo progressivo de urbanização e a crescente concentração de resíduos sólidos no espaço urbano estabelecem a problemática da destinação do resíduo sólido urbano.

Campo Grande, capital de Mato Grosso do Sul, e situa-se no Centro Oeste brasileiro, ocupando 2,26 \% da área total do Estado, correspondendo a $8.096 \mathrm{~km}^{2}$, dos quais $154,45 \mathrm{~km}^{2}$ são área urbana. Os $98.6 \%$ da população residente na zona urbana produzem aproximadamente 800 toneladas dia de resíduos. A destinação adequada e sustentável dos resíduos é de extrema importância em conformidade com que estabelece a Lei no $12.305 / 2010$, regulamentada pelo Decreto $n$ 0 7.404/2010 que instituiu a Política Nacional de Resíduos Sólidos.

Ao destacar o panorama dos resíduos sólidos urbanos recicláveis em Campo Grande - MS e identificar as lacunas ou entraves na estrutura sistêmica que colaboram com a disfuncionalidade da dinâmica no descarte desses resíduos o trabalho fundamenta-se cientificamente. A pesquisa contou com a colaboração das empresas CG SOLURB Soluções Ambientais - SPE Ltda., concessionária responsável pela gestão da Limpeza Urbana e o Manejo de Resíduos

1 MsC no PPG Desenvolvimento Local-UCDB. Campo Grande. Mato Grosso do Sul/ MS.

2 Dr em Desarrollo Local y Planteamiento Territorial. PPG Desenvolvimento Local-UCDB. Campo Grande. Mato Grosso do Sul/ MS.

3 Dr. em Ciências Florestais. UCDB. Campo Grande. Mato Grosso do Sul/ MS.

4 Dr. em Ciências Sociais. UCDB. Campo Grande. Mato Grosso do Sul/ MS.

- O Trabalho é resultado do Grupo Pesquisa CNPq - Economia Criativa, Aprendizagem e a Solidariedade Ativa na Dinâmica Territorial, na área de Planejamento Urbano e Regional. 
Sólidos do município de Campo Grande, a empresa Reciclagem e Preservação Ambiental (REPRAM) e a ENERGISA, concessionária de energia elétrica de Mato Grosso do Sul.

Discorre-se ainda, no presente trabalho sobre os mecanismos catalizadores de ações que se apresentam como alternativas de resolução da gestão e destinação adequada dos resíduos sólidos urbanos recicláveis, sobrelevando os conceitos mais difundidos sobre desenvolvimento sustentável. Igualmente a Economia Criativa emergiu no cenário a partir das potencialidades locais empreendedoras como uma inovação criativa com alto poder econômico. Serão demonstrados os dados na pesquisa de campo referentes aos anos de 2013, 2014, 2015 e 2016 até agosto.

\section{DESENVOLVIMENTO SUSTENTÁVEL}

O termo sustentabilidade tem duas origens segundo Nascimento (2012, p. 51), a primeira em biologia com as especificidades da ecologia quanto "à capacidade de recuperação e reprodução dos ecossistemas (resiliência) em face de agressões antrópicas ou naturais". E, a segunda, econômica, como adjetivação de desenvolvimento que frente às apreensões progressivas do século $\mathrm{XX}$, "demonstram que o padrão de produção e consumo em expansão no mundo, [...] não tem possibilidade de perdurar".

O contexto que levou o mundo a essa percepção data entre os anos de 1950 e 1962, onde os países com poderio atômico efetuaram 423 detonações atômicas. Em decorrência, em 1968 a Suécia propôs ao Conselho Econômico e Social das Nações Unidas uma conferência um acordo internacional de redução da emissão dos gases responsáveis pelas chuvas ácidas. A Conferência de Estocolmo em 1972 foi o primeiro evento mundial a discutir sustentabilidade. Concomitante à Conferência de Estocolmo, os trabalhos de Nicholas Georgescu - Roegen expôs a economia como um "subsistema da ecologia, interagindo com a natureza em seu processo de transformação, baseado na segunda lei da termodinâmica". Já Arne Naess, publicou um trabalho diferenciando "ecologia superficial e ecologia profunda" (NASCIMENTO, 2012, p. 54).

Em 1987, a norueguesa Gro Harlen Brundtland, responsável pelo relatório intitulado Our common future, propôs uma agenda global 
vislumbrando instaurar um paradigma entre preservação ambiental e desenvolvimento econômico. Para Lenzi apud Nascimento (2012, p. 54), “Desenvolvimento sustentável é o desenvolvimento que satisfaz as necessidades do presente sem comprometer a capacidade das gerações futuras em satisfazer suas próprias necessidades".

O Clube de Roma redigiu um relatório em 1972 se posicionando contra o crescimento econômico, intitulado Limits to Growth, propondo "a desaceleração do desenvolvimento industrial nos países desenvolvidos, e do crescimento populacional, nos países subdesenvolvidos" (NASCIMENTO, 2012, p. 53).

Por sua vez Latouche (2010) descreve que o desenvolvimento sustentável é uma ilusão para manter a economia produtivista, bem como uma resiliência do imaginário progressista. Para o autor, falar em desenvolvimento sustentável é valer-se de manipulações semânticas, sendo preciso romper com os padrões de produção e consumo para sedimentar o decrescimento na economia que objetiva excessivamente o lucro e estabelecer novos modelos de vida, consagrando a homeostase da condição humana e o meio ambiente. Em 1992 a ONU convocou a Conferência das Nações Unidas para o Meio Ambiente e o Desenvolvimento (Cnumad) que ganhou notoriedade como Rio-92 e repercutiu com a criação da Convenção da Biodiversidade e das Mudanças Climáticas resultando no Protocolo de Kyoto, e na Declaração do Rio e a Agenda 21.

Para que haja a incorporação, disseminação e efetivação dos princípios do desenvolvimento sustentável, mister a participação social de forma inter-relacionada e sistêmica, considerando que o desenvolvimento é em si mais um processo que um fim, haja vistas as constantes mutações das necessidades sociais.

\section{O DESENVOLVIMENTO LOCAL COMO FATOR DO DESENVOLVIMENTO SUSTENTÁVEL}

Ainda que a forma disseminada de desenvolvimento sustentável seja apenas uma protelação da verdadeira estrutura sistêmica equilibrada, é preciso lembrar que um dos princípios do desenvolvimento local é processo gradativo de desabrochar.

A despeito de todas as iniciativas governamentais e organizacionais a evolução do processo de desenvolvimento sustentável 
ainda é muito tímida e inexpressiva, apesar da necessidade urgente de remodelação dos modos de vida, produção e consumo. Quando se discute apenas o contexto ambiental, econômico e social se distancia a imprescindibilidade do engajamento social em todo o processo de mudança paradigmática. $O$ desenvolvimento sustentável é um somatório de fatores dinâmicos e ressonantes e como tal, para que se materialize, é necessário que haja a metabolização dos potenciais exógeno e endógenos

\section{O desenvolvimento local como ferramenta para o desenvolvimento integrado}

O desenvolvimento local apresenta alguns conceitos e alternativas para promoverem a transformação social propagando e incorporando princípios do desenvolvimento sustentável que muitas vezes se misturam com aquele. A participação dos agentes de desenvolvimento local é fundamental na construção desse novo modelo, haja vista sua capacidade de catalisar energia, estimular as sinergias locais e as estruturas em rede.

O desenvolvimento local é capaz de identificar as peculiaridades do território e favorecer o desenvolvimento endógeno sistêmico, multi e inter-relacionado.

O desenvolvimento local é ferramenta de humanização do desenvolvimento sustentável, em especial porque propõe novos conceitos sobre qualidade de vida e valorização da condição humana. Para que haja a correspondência sistêmica dentro do território local e também em rede, o desenvolvimento local funciona como uma sinergia autopoiética que compreende a dinâmica estrutural e remodela o pensamento linear sem alterar a organização essencial e desconfigurar a especificidade do território.

\section{ALTERNATIVAS PROMOTORAS DE DESENVOLVIMENTO SUSTENTÁVEL PARA O RESÍDUO SÓLIDO URBANO RECICLÁVEL}

Neste tópico será demonstrado que a economia criativa e a logística reversa são alternativas já utilizadas no município de Campo Grande no que tange à destinação dos resíduos sólidos urbanos 
recicláveis, entretanto, ainda é preciso trabalhar a identificação e vinculação da comunidade local no processo para potencialização do desenvolvimento sustentável.

\section{A economia criativa}

O pensamento econômico fora construído por pessoas que não eram intituladas economistas, mas, sobretudo que buscavam compreender suas próprias atividades, bem como aquelas que lhes circundavam valendo-se de suas experiências empíricas.

Considerando a produção da vida material, à medida que esta extrapola os limites do autoconsumo, o valor atribuído aos seus produtos deixa de ser apenas de uso e passa a ter um valor de troca, é nesse momento, revestido por decisões conscientes que ocorre a vida econômica.

A economia de mercado foi um importante elo entre os locais de produção e as cidades, essa movimentação no tecer do tempo favoreceu a expansão e fortalecimento das inúmeras economias de mercado que hoje transformaram a economia mundial em um tecido de fibras imbricadas, interdependentes e multifacetadas. Segundo Bairoch apud Comparato (2013, p. 89) "na civilização capitalista a técnica somente produz transformações sociais quando dinamizada pelo investimento econômico". Essa busca pelo crescimento acelerado de riquezas não produziu prosperidade igualitária à sociedade, ao contrário, seguiu objetivando a expansão e concentração do poderio político econômico capitalista.

Em meio à expansão econômica financeira e especulativa fundamentada em alicerces conceituais do capitalismo pós-industrial alguns Estados e organizações internacionais começaram a buscar meios alternativos de resgate da economia local baseada na cultura, no conhecimento e tecnologia. Desta feita, em:

04 de dezembro de 1986, a ONU editou a primeira Declaração sobre o Direito ao Desenvolvimento, afirmando que o mesmo é um direito humano inalienável, ao mesmo tempo em que é um direito e dever dos Estados" (Plano da Secretária de Economia Criativa). Tal fato estimulou o governo federal da Austrália - [...]-que em 1994 propôs um projeto de nova política cultural, Creative Nation, objetivando "preservar e valorizar o 
patrimônio cultural nacional em toda a sua diversidade, sem descuidar do desenvolvimento dos setores relacionados às novas tecnologias (SERRA; FERNANDES, 2014, p. 357).

A expressão economia criativa deve-se ao artigo do jornalista Peter Coy, publicado pela revista Businessweek no ano 2000, o qual ressaltava o papel das empresas na nova economia do conhecimento que estaria se formando. A economia criativa surgiu no mercado como um sistema imbricado de práxis econômicas com acentuado conteúdo intangível vinculado às artes, à cultura, às novas mídias e à criatividade em geral, reivindicando assim, habilidades cada vez mais especializadas da força de trabalho, bem como adequação ao desenvolvimento científico-tecnológico.

O envolvimento da Organização das Nações Unidas para a Educação, a Ciência e a Cultura (UNESCO) e da Conferência das Nações Unidas para o Comércio e Desenvolvimento (UNCTAD) foi substancial para que a economia criativa pudesse ganhar corpo e se adaptar às especificidades econômicas locais. A UNCTAD tem impelido um eloquente esforço na produção e dispersão de conhecimento sobre economia criativa.

Ainda não se chegou a um conceito preciso de economia criativa. Ademais, destaca-se a importância dada à compreensão dos agentes que se propõem trabalhar com a economia criativa, bem como na importância das atividades assumidas nas diferentes nações e esferas governamentais que as promovem e monitoram.

A economia criativa, que integra a economia do conhecimento, se apresenta como um novo campo de estudos no qual emergem questões como o papel da criatividade e dos talentos individuais na produção, a natureza dos produtos criativos e de suas cadeias produtivas, a potencial geração de valor na forma de direitos de propriedade intelectual e a própria relação entre tecnologia e arte (SERRA; FERNADEZ, 2014. p. 361).

A UNESCO criou em 2004 uma rede de Cidades Criativas que movimenta informações e experiências que estimulam as possibilidades de desenvolvimento local com aptidões criativas, que em 2014 já somava 69 cidades das mais diferentes nacionalidades. 0 selo possui sete categorias criativas, artesanato e artes folclóricas, design, cinema, gastronomia, literatura, artes midiáticas e música. 
O Brasil participa com 5 cidades: Belém e Florianópolis na categoria gastronomia, Salvador na categoria música, Santos na categoria cinema, Curitiba na categoria design. A economia criativa tem se nutrido das especificidades naturais, culturais e tecnológicas de cada localidade. Importante destacar o potencial empregador e gerador de renda da classe mais jovem da população:

O potencial empregador, produtivo e inovativo das atividades culturais e criativas é ainda relativamente pouco estudado, mas sua potência já é visível. Resistências têm sido quebradas ao se constatar que as atividades criativas figuram entre as que mais vêm contribuindo para o crescimento de muitas economias em desenvolvimento. Tornou-se, portanto, necessário e relevante conceber novos instrumentos, metodologias e indicadores capazes de entender e de promover economicamente tais atividades (PLANO DA [EXTINTA] SECRETARIA DE ECONOMIA CRIATIVA, p. 09).

Dentro desse conceito de valorização das culturas nacionais foi estabelecido pelo Ministério da Cultura a Figura 1, que ilustra os objetos da economia criativa.

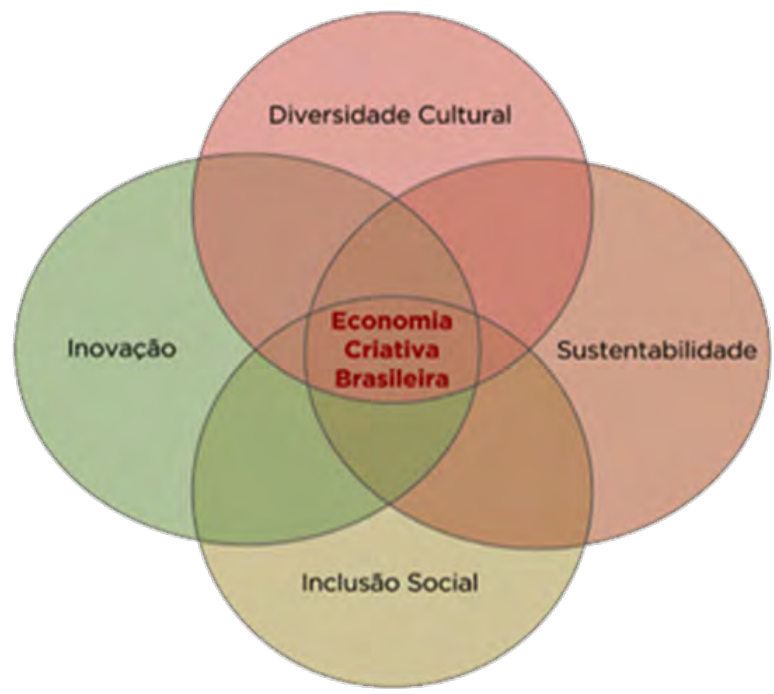

Figura 1. Sistema de economia criativa brasileira segundo Ministério da Cultura do Brasil.

Fonte: Ministério da Cultura. 
Denota-se que no Brasil existe a preocupação de construir uma economia criativa de forma simbiótica, estabelecendo as esferas da diversidade cultural, sustentabilidade, inclusão social, inovação como princípios norteadores e edificadores da realidade nacional. Funciona como se cada segmento fosse uma unidade geradora de energia que juntas estabelecem conexões sinérgicas promotoras de desenvolvimento local.

\section{Logística reversa}

Este tópico trata de alternativas para o descarte adequado do resíduo sólido urbano reciclável de Campo Grande-MS, bem como soluções que promovam desenvolvimento local dos núcleos envolvidos. A constante e ascendente extração de matérias primas naturais esgota o capital natural, além de mitigar as necessidades para a manutenção do capital humano. À medida que estudos científicos demonstram este cenário e cada vez mais pessoas têm acesso à informação, a sociedade aos poucos desperta para novos padrões de vida buscando meios inovadores e alternativos para a destinação dos resíduos gerados, bem como seu reaproveitamento nos ciclos produtivos.

Inovações que atuem de forma integrada consoante aos princípios da ecologia humana ganham cada vez mais espaço. Entre as alternativas, a logística reversa figura como uma inovação eficiente e rentável para a destinação sustentável dos resíduos gerados.

Segundo Martendal e Santos (2014), a logística se subdivide em quatro áreas operacionais, i) logística de suprimentos que compreende as atividades necessárias para suprir as necessidades de insumos materiais da empresa; ii) logística de apoio à manufatura que planeja, armazena e controla os fluxos internos; iii) logística de distribuição que é responsável pela entrega e iiii) logística reversa que "é a mais nova área da logística e é responsável pelo retorno dos produtos de pós-venda e de pós-consumo e de seu endereçamento a diversos destinos". Martendal e Santos propõem a seguinte definição de logística reversa:

A logística reversa pode ser entendida como o fluxo de materiais no sentido contrário àquele que vai dos fornecedores de matérias-primas para o usuário (CORRÊA apud MARTENDAL 
e SANTOS, 2014, p.2), podendo agregar também operações e ações ligadas, desde a redução de matérias-primas até a destinação final correta de produtos, materiais e embalagens com o seu posterior reuso, reciclagem ou produção de energia (PEREIRA apud MARTENDAL e SANTOS, 2014, p. 2).

Em 2010, a Lei no 12.305 regulamentou a Política Nacional de Resíduos Sólidos (PNRS) definindo em seu texto legal o que seria logística reversa:

[...] instrumento de desenvolvimento econômico e social caracterizado por um conjunto de ações, procedimentos e meios destinados a viabilizar a coleta e a restituição dos resíduos sólidos ao setor empresarial, para reaproveitamento, em seu ciclo ou em outros ciclos produtivos, ou outra destinação final ambientalmente adequada (Lei no 12.305/2010)

Apesar da determinação legal, é possível perceber que a sociedade não adere de pronto às iniciativas que rompem com padrões pré-estabelecidos, é preciso que agentes de desenvolvimento local atuem junto aos grupos destinatários. Neste processo, a logística reversa apresenta-se com extrema importância na resolução da destinação adequada ao resíduo sólido urbano.

\section{Conta cidadã}

Considerando a importância da economia criativa e da logística reversa como instrumentos de desenvolvimento local no que se refere a resíduo sólido urbano, nesse tópico será exemplificando uma iniciativa no município de Campo Grande - MS. A iniciativa se trata de um projeto instituído em atendimento à Lei no 9.991 de 24 de julho de 2000 que determinou sobre a necessidade das empresas do setor energético investirem em pesquisa, desenvolvimento e eficiência energética.

Art. 1ำ As concessionárias e permissionárias de serviços públicos de distribuição de energia elétrica ficam obrigadas a aplicar, anualmente, o montante de, no mínimo, setenta e cinco centésimos por cento de sua receita operacional líquida em pesquisa e desenvolvimento do setor elétrico e, no mínimo, vinte e cinco centésimos por cento em programas de eficiência energética no uso final [...] 
Em outubro de 2015 foi aprovado pela concessionária energética de Mato Grosso do Sul, Energisa, o projeto Conta Cidadã. Segundo Emerson Rivelino, coordenador do Projeto Conta Cidadã consiste na troca de resíduo urbano reciclável por créditos financeiros na fatura de energia elétrica dos consumidores, com destinação organizada do material coletado ao processo industrial de reciclagem.

O projeto acontece só em Campo Grande-MS e até o dia 19 de novembro de 2016 possuía 4469 unidades consumidoras cadastradas. São 6 postos de coleta e em pouco mais de 7 meses de atuação 290 toneladas de resíduos recicláveis já foram recolhidos e gerando uma economia nas faturas energéticas de 27 mil reais.

\section{O PANORAMA DOS RESÍDUOS SÓLIDOS URBANOS RECICLÁVEIS EM CAMPO GRANDE - MS}

O resíduo de que se trata neste trabalho é o domiciliar e comercial resultante do descarte proveniente das atividades humanas. A questão transformou-se em um dos grandes desafios a serem equacionados pela sociedade moderna.

\section{Cenário dos resíduos sólidos urbanos no Estado de Mato Grosso do Sul}

Serão demonstrados alguns dados do Estado para que se possa comparar a realidade de Campo Grande. Mato Grosso do Sul tem aproximadamente 2,6 milhões de habitantes que equivalem a $1,25 \%$ da população nacional e Campo Grande possui aproximadamente 864 mil habitantes, dos quais 98,6\% concentram-se na zona urbana. Alega a concessionária de limpeza que o município campo-grandense gera em média 800 t/dia de RSU (Tabela 1).

\begin{tabular}{ccc}
\hline & MS & CAMPO GRANDE \\
\hline QUANTIDADE DE HABITANTES & 2,6 MILHÕES & 864 MIL \\
\hline GERAÇÃO DE RSU & $2.642 \mathrm{t} /$ DIA & $800 \mathrm{t} / \mathrm{DIA}$ \\
\hline
\end{tabular}

Tabela 1. Comparativo de geração média de RSU entre MS e CG

Fonte: Construção dos autores, adaptado de Abrelpe e SOLURB. 2017.

Mato Grosso do Sul gerou $2.642 \mathrm{t} /$ dia de RSU, dos quais foram coletados 2,412 t/dia. Desse total, 40,1\% (967 t/dia) foram destinados a aterros sanitários, 29,9\% (722 t/dia) a aterros controlados e 
$30 \%$ (723 t/dia) a lixões. Comparativo com dados de Mato Grosso do Sul (Figura 2).

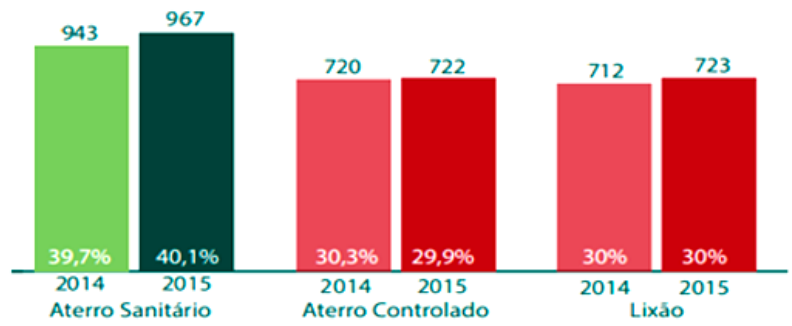

Figura 2. Destinação do RSU em Mato grosso do Sul (t/dia)

Fonte: Pesquisa Abrelpe/IBGE

Panorama dos dados coletados no município de Campo Grande

Seguem os dados coletados nas empresas campo-grandenses que têm como atividade econômica a manipulação dos resíduos sólidos do município, sejam eles, recicláveis ou não.

\section{SOLURB}

A empresa CG SOLURB Soluções Ambientais - SPE Ltda. é a concessionária responsável pela gestão da Limpeza Urbana e o Manejo de Resíduos Sólidos de Campo Grande - MS. Dados dos anos de 2013, 2014, 2015 e 2016 até agosto (Tabela 2).

\begin{tabular}{ccccc}
\hline \multicolumn{5}{c}{ SOLURB COLETA $(\mathbf{t})$} \\
\hline JANEIRO & 2013 & 2014 & 2015 & 2016 \\
\hline FEVEREIRO & $24.167,90$ & $27.393,58$ & $25.541,96$ & $25.174,43$ \\
\hline MARÇO & $20.137,39$ & $21.438,24$ & $21.765,40$ & $23.148,46$ \\
\hline ABRIL & $21.021,41$ & $21.798,20$ & $23.340,37$ & $23.498,10$ \\
\hline MAIO & $20.975,66$ & $21.392,08$ & $21.907,15$ & $21.423,87$ \\
\hline JUNHO & $20.328,95$ & $20.807,99$ & $21.375,94$ & $20.795,57$ \\
\hline JULHO & $19.140,10$ & $19.921,20$ & $21.807,74$ & $19.325,79$ \\
\hline AGOSTO & $20.413,14$ & $21.141,41$ & $21.713,79$ & $19.783,76$ \\
\hline & $19.383,11$ & $20.681,57$ & $21.044,62$ & $20.752,76$ \\
\hline
\end{tabular}




\begin{tabular}{ccccc}
\hline SETEMBRO & $19.640,20$ & $22.378,46$ & $18.877,22$ & - \\
\hline OUTUBRO & $22.144,14$ & $23.733,13$ & $21.612,62$ & - \\
\hline NOVEMBRO & $21.939,38$ & $22.987,72$ & $23.475,16$ & - \\
\hline DEZEMBRO & $25.208,30$ & $27.978,16$ & $27.491,22$ & - \\
\hline TOTAL & $254.499,68$ & $271.651,74$ & $269.953,19$ & $173.902,74$ \\
\hline
\end{tabular}

Tabela 2. Coleta de RSU: SOLURB 2013/2016

Fonte: Construção dos autores, dados SOLURB

A Solurb possui um programa de coleta seletiva que iniciou em 01.07.2011 e até 28.09.2016 beneficiava 33 setores de Campo Grande. Somente em 28.08.2015 foi inaugurada a Usina de Triagem de Resíduos (UTR), conforme Tabela 3.

\begin{tabular}{lccccc}
\hline \multicolumn{5}{c}{2015} \\
& Setembro & Outubro & Novembro & Dezembro & Total \\
\hline Recicláveis $(\mathrm{t})$ & 124,21 & 238,89 & 325,91 & 398,38 & $1.087,39$ \\
\hline Rejeitos(t) & 126,13 & 149,47 & 135,71 & 126,78 & 538,09 \\
\hline
\end{tabular}

Tabela 3. Coleta seletiva para UTR 2015

Fonte: Construção dos autores, dados SOLURB, 2017.

A SOLURB disponibilizou os dados sobre os resíduos recicláveis da coleta seletiva que são encaminhados para a UTR. Ressalta-se que as tabelas 3 e 4 apresentam dados de alguns meses do segundo semestre de 2015, haja vista que o inicio das atividades se deu em agosto desse ano, e do ano de 2016 até o mês de agosto (Tabela 4).

\begin{tabular}{lllllllll}
\hline \multicolumn{8}{c}{2016} \\
\hline Jan & Fev & Mar & Abr & Mai & Jun & Jul & Ago & Total \\
\hline
\end{tabular}

Recicláveis

(t)

$360,18320,62 \quad 345,08365,93363,740 \quad 375,860400,650 \quad 398,3502.930,41$

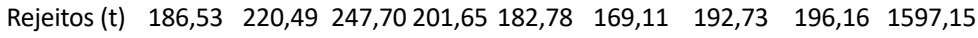

Tabela 4. Coleta seletiva para UTR 2016

Fonte: Construção dos autores, dados SOLURB, 2017.

Consta nas duas tabelas acima a indicação de recicláveis e rejeitos, estes se referem ao material recolhido na coleta seletiva 
feita pela SOLURB, mas que fora descartado inadequadamente, e por essa razão são desprezados e encaminhados ao aterro sanitário.

\section{REPRAM}

A REPRAM é uma empresa local que iniciou as atividades em 1991 e no ano de 2015 foi vendida a Sirka- Participações que pertence ao Grupo Penido Holdings. Hoje, a empresa possui duas filiais, sendo uma em Rondonópolis-MT e outra em Volta Redonda-RJ e a sede de Campo Grande busca cada vez mais se adequar às exigências de mercado tanto quanto as ambientais, prova disso é a obtenção do Selo Verde (Figura 3).

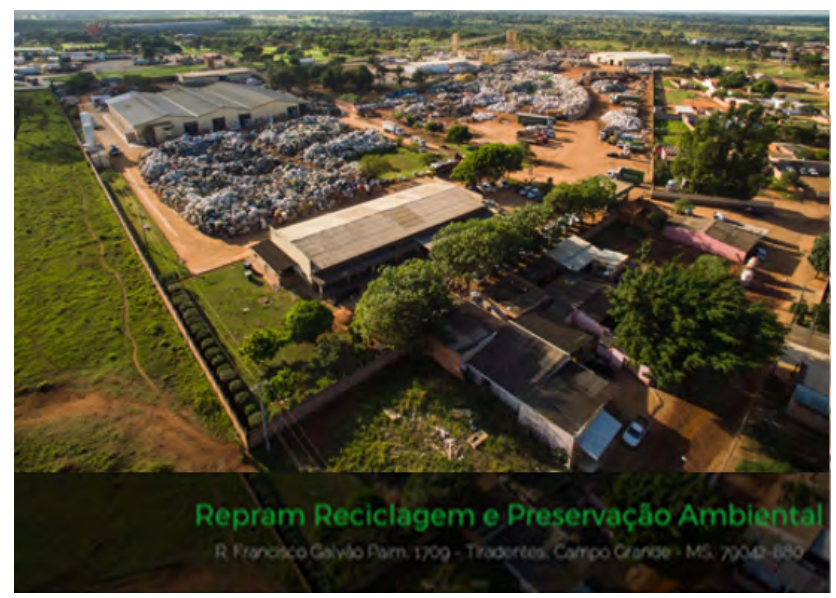

Figura 3. Vista aérea REPRAM. Fonte: Acervo dos autores. 2017.

A empresa trabalha com todo tipo de resíduos e recebe cerca de 220 t/dia de resíduos recicláveis. Os rejeitos orgânicos são encaminhados para a Organoeste, empresa produtora de adubo. Rejeitos com alto poder de contaminação são encaminhados para unidades de tratamento em Três Lagoas-MS.

A maior parte do material tem origem em Mato Grosso do Sul, porém, Mato Grosso é um grande fornecedor, assim como Acre e Rondônia. Em contrapartida, em entrevista com um dos clientes da empresa, da cidade de Ponta Porã, constatou-se que das 150 t/mês de material reciclável que coleta $70 \%$ é de origem paraguaia (Tabela 5). 


\begin{tabular}{|c|c|c|}
\hline \multicolumn{3}{|c|}{ ANO 2013} \\
\hline TIPO/CATEGORIA & PESO EM KG & $\begin{array}{c}\text { PREÇO MÉDIO EM } \\
\text { REAIS }\end{array}$ \\
\hline PAPEL & $25.979 .766,500$ & 0,31972 \\
\hline PLASTICO & $16.120 .687,800$ & 0,94424 \\
\hline ALUMINIO & $4.770 .107,00$ & 2.81742 \\
\hline OUTROS METAIS & $621.304,900$ & 2,74776 \\
\hline COBRE & $783.107,500$ & 12,49832 \\
\hline FERRO & $3.069 .128,600$ & 0,28840 \\
\hline VIDRO & $382.070,000$ & 0,04879 \\
\hline TOTAL EM KG & $51.726 .172,300$ & ------------------ \\
\hline PAPEL & $26.812 .117,700$ & 0,35253 \\
\hline PLASTICO & $16.055 .390,935$ & 1,09946 \\
\hline ALUMINIO & $5.774 .058,331$ & 3,25035 \\
\hline OUTROS METAIS & $642.108,195$ & 2,72766 \\
\hline COBRE & $869.401,965$ & 12,73329 \\
\hline FERRO & $2.559 .984,900$ & 0,31301 \\
\hline VIDRO & $432.720,000$ & 0,05000 \\
\hline TOTAL EM KG & $53.145 .782,026$ & ---------------------- \\
\hline PAPEL & $25.313 .733,330$ & 0,28494 \\
\hline PLASTICO & $16.614 .439,657$ & 1,06952 \\
\hline ALUMINIO & $5.111 .134,848$ & 3,69446 \\
\hline OUTROS METAIS & 536.719 .255 & 3,02747 \\
\hline COBRE & $802.055,445$ & 12,87829 \\
\hline FERRO & $3.086 .709,800$ & 0,32200 \\
\hline VIDRO & $412.220,000$ & 0,05000 \\
\hline TOTAL EM KG & $51.877 .012,335$ & - \\
\hline PAPEL & $15.172 .023,008$ & 0,33375 \\
\hline PLASTICO & $10.484 .746,384$ & 0,91142 \\
\hline ALUMINIO & 2. $645.560,678$ & 3,78012 \\
\hline OUTROS METAIS & $502.692,650$ & 2,63350 \\
\hline COBRE & $410.645,065$ & 13,03756 \\
\hline FERRO & $2.230 .240,600$ & 0,25809 \\
\hline VIDRO & $172.321,500$ & 0,05000 \\
\hline TOTAL EM KG & $31.618 .229,885$ & ---------------------- \\
\hline
\end{tabular}

Tabela 5. Recicláveis da REPRAM dos anos de 2013,2014,2015 e 2016 até agosto Fonte: Construção dos autores, dados REPRAM. 
Pelo volume de recicláveis manipulados pela REPRAM denota-se a importância dessa empresa na dinâmica do resíduo sólido reciclável em Campo Grande. Tanto os materiais recolhidos pela SOLURB, seja pela coleta tradicional ou seletiva, quanto os recolhidos pela Energisa são encaminhados para a REPRAM que dispõe da estrutura necessária à destinação dos resíduos recicláveis.

\section{Análise comparativa dos dados quantitativos coletados}

Para compreender o panorama dos resíduos sólidos recicláveis em Campo Grande, será feita análise correlativa dos dados coletados durante a pesquisa de campo. A tabela n.6 apresenta a quantidade resíduo sólido urbano geral coletado pela SOLURB e o resíduo urbano reciclável trabalhado pela REPRAM (Tabela 6).

\begin{tabular}{cccc}
\hline \multicolumn{4}{c}{ RESIDUOS URBANO GERAL (t) } \\
\hline 2013 & 2014 & 2015 & 1016 \\
\hline $254.499,68$ & $271.651,74$ & $269.953,19$ & $173,902,74$ \\
\hline \multicolumn{4}{c}{ RESIDUO URBANO RECICLAVEL(t) } \\
\hline $51.726,17$ & 2014 & 2105 & 1016 \\
\hline \multicolumn{4}{c}{$51.616,23$} \\
\hline
\end{tabular}

Tabela 6. Resíduos urbanos: comparativos com resíduos recicláveis. Fonte: Construção dos autores, dados SOLURB e REPRAM

Observa-se nesta Tabela acima o pouco aproveitamento econômico do resíduo urbano reciclável. É evidente a potencialidade de crescimento, entretanto, a dinâmica social divergente não favorece o desenvolvimento. As políticas públicas e interesse econômico existentes se tornam insuficientes frente a ausência de envolvimento social pró-ativo dos munícipes (Figura 4). 


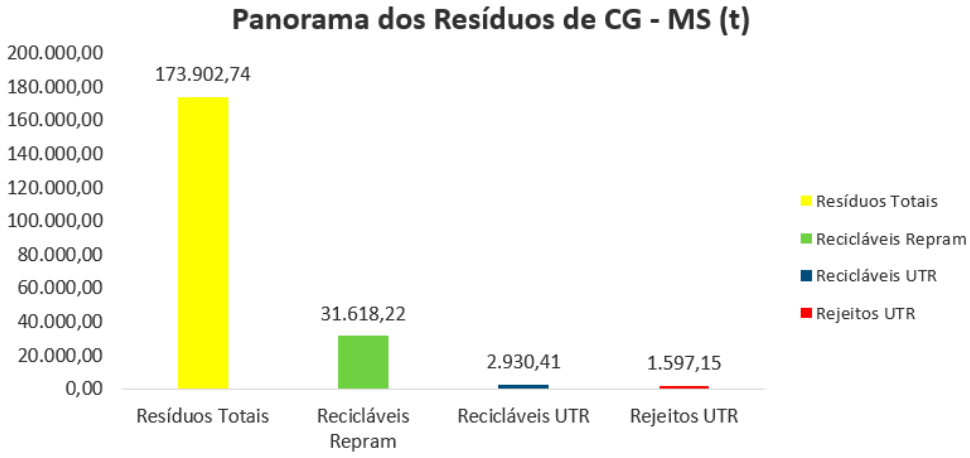

Figura 4. Comparativo do Resíduo Sólido de Campo Grande - MS Jan/Ago 2016 Fonte: Construção dos autores, dados SOLURB e Repram.

Para comparar com o gráfico acima que se refere ao mês de agosto de 2016, apresenta-se o resultado de pesquisas feitas em Campo Grande em dois períodos distintos. Peixoto Filho, Sanches de Oliveira e Costa de Oliveira $(2007$, p.3) demonstraram que em 2006 63\% do RSU constituíam matéria orgânica, 32\% RSU reciclável e $5 \%$ eram de origem diversa. Já Tenório $(2015$, p.80) descreveu que em 2014 o RSU orgânico era 43,8\%, RSU reciclável era 41,4\% e $15,8 \%$ de origem diversa. Denota-se que em oito anos houve um aumento de $9,4 \%$ na quantidade de RSU reciclável encaminhada ao aterro (Figura 5).

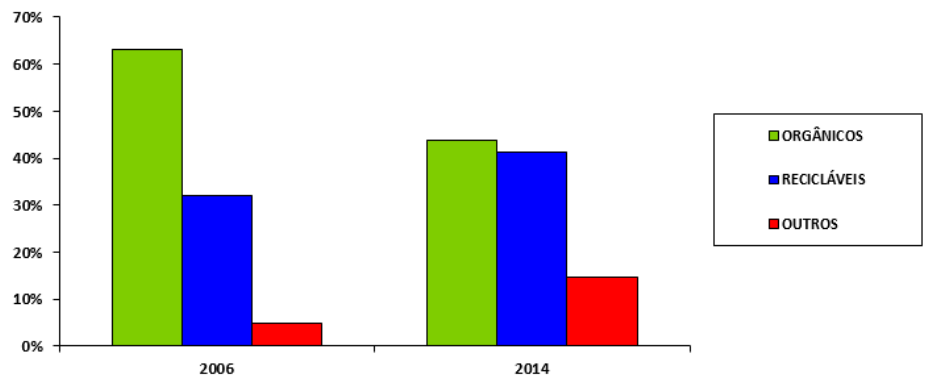

Figura 5. Comparativo entre RSU e RSU reciclável dos anos de 2006 e 2014 Fonte: Construção dos autores, dados de SOLURB e REPRAM 
Nessa tabela será demonstrado o percentual de cada tipo RSU reciclável contido nas amostragens recolhidas no aterro de Campo Grande pelos Peixoto Filho, Sanches de Oliveira e Costa de Oliveira (2007, p.3), no ano de 2006 e por Tenório no ano de 2014 (Tabela 7).

\begin{tabular}{ccccc}
\hline MATERIAIS & $\begin{array}{c}\text { PAPEL/ } \\
\text { PAPELÃO }\end{array}$ & $\begin{array}{c}\text { PLÁstICO } \\
\text { DURO E } \\
\text { MOLE }\end{array}$ & $\begin{array}{c}\text { METAIS FERROSOS E } \\
\text { NÃO FERROSOS }\end{array}$ & VIDRO \\
\hline 2006 & $15 \%$ & $12 \%$ & $3 \%$ & $2 \%$ \\
\hline 2014 & $20,66 \%$ & $14,91 \%$ & $2,03 \%$ & $3,8 \%$ \\
\hline
\end{tabular}

Tabela 7. Porcentagem de RSU reciclável destinado ao aterro nas amostras de 2006 e 2014

Fonte: Construção dos autores, dados obtidos nas pesquisas de Peixoto Filho, Sanches de Oliveira e Costa de Oliveira $(2007$, p.3) e Tenório $(2015$, p. 80$)$.

A próxima tabela apresenta da constituição dos materiais contidos na mesma amostragem acima denominados por origem diversa (Tabela 8).

\begin{tabular}{c|c|c|c|c|c}
\hline PERDAS & $\begin{array}{c}\text { BORRACHA } \\
\text { COURO }\end{array}$ & $\begin{array}{c}\text { PANO E } \\
\text { ESTOPA }\end{array}$ & MADEIRA & PEDRAS & OUTROS \\
\hline 2006 & $1 \%$ & 2 & 1 & $1 \%$ & \\
\hline 2014 & $4 \%$ & 1,87 & 1,18 & & 8,77 \\
\hline
\end{tabular}

Tabela 8. Descrição da constituição dos materiais de origem diversa contidos na mesma amostragem citada na tabela anterior

Fonte: Construção dos autores, dados obtidos nas pesquisas de Peixoto Filho, Sanches de Oliveira e Costa de Oliveira $(2007$, p.3) e Tenório $(2015$, p. 80$)$.

Destaca-se que o RSU reciclável da UTR é proveniente da coleta seletiva, portanto, não engloba esse montante, todavia, aproximadamente $50 \%$ do material reciclável recolhido vira rejeito por inadequação no descarte, ou seja, materiais sujos com resquícios de matéria orgânica (leite, suco, margarinas, shampoos).

Considerando os dados disponibilizados pela Soburb e a estimativa feita acima, no mês de agosto de 2016 e somando os rejeitos da UTR de 196,16 (t) e o valor suposto pela estimativa, o aterro sanitário de Campo Grande recebeu 73,196 (t) de RSU reciclável. Esse material foi depositado no meio ambiente mesmo possuindo valor econômico e sendo a fonte de renda dos coletores. 


\section{Retrato da realidade dos coletores}

Essa parte do trabalho está orientada por revisão bibliográfica da imprensa local que vem retratando a realidade dos trabalhadores coletores de recicláveis do município de Campo Grande com o fechamento do aterro e a instituição da UTR. Os coletores são um elo importante e também vulnerável da cadeia produtiva na destinação adequada e aproveitamento dos RSU recicláveis. A dinâmica sistêmica dessa cadeia tem como agentes os geradores, os coletores do material reciclável e os compradores desse material, responsáveis por encaminhar os RSU recicláveis à indústria.

Observa-se que existe uma disfunção sistêmica em relação aos geradores, pois a parte que lhes compete, ou seja, a seleção e descarte adequado do resíduo não está sendo feita. Por essa razão cerca de $42 \%$ do RSU reciclável gerado em Campo Grande estão sendo desperdiçados no aterro sanitário, degradando o meio ambiente e contribuindo com a situação de vulnerabilidade dos trabalhadores, tanto os cooperados da UTR, quanto aqueles não conseguiram participar das cooperativas.

O lixão de Campo Grande funcionou por 28 anos e em novembro de 2012 foi fechado, entretanto, por força de decisão judicial em resposta ao pedido feito pela Defensoria Pública, em janeiro de 2013 foi reaberto. Segundo a defensoria muitos trabalhadores dependiam do local para manutenção da sua subsistência, razão pela qual foi criada uma zona de transição dentro do aterro sanitário, contudo, em fevereiro de 2016 o aterro foi fechado definitivamente.

A UTR foi inaugura em 14.08.2015 com capacidade para receber 400 trabalhadores, funcionar em 3 turnos ininterruptos de 8 horas cada e reciclar 150 (t) por dia, entretanto, muito embora toda a estrutura disponibilizada, a quantidade de RSU reciclável recebido diariamente é insuficiente, cerca de 13 (t) dia e conforme descrito neste trabalho cerca de aproximadamente $50 \%$ vira rejeito. Lima e Marques (2015) divulgaram que antes do fechamento do aterro a renda mensal média dos trabalhadores era de $R \$ 3.000,00$ reais e Castelar (2016) informou que trabalhadores que vendiam em um Domingo de $\mathrm{R} \$ 900,00$ a $\mathrm{R} \$ 1.000,00$ reais, atualmente não alcançavam o valor de $R \$ 300,00$ reais. 
A prefeitura municipal chegou a oferecer auxílios, como o vale renda e o bolsa família até que os coletores se reinserissem no mercado de trabalho, entretanto, isso causou revolta em alguns que não aceitam sobreviver nessas condições. "Segundo o catador Jeferson Osmar, antes não era preciso ajuda do governo para financiar uma moto ou ir no mercado comprar o que precisava ou tinha vontade. Prefiro meu emprego de volta ao invés de um benefício social" (CASTELA, 2016).

Essa situação ocasionada pelo fechamento definitivo do aterro e a insuficiência de RSU reciclável na URT está favorecendo um movimento migratório dentro do município. Os trabalhadores estão migrando para uma área municipal destinada a entulhos. Entretanto, apesar da destinação do local ser especifica para entulhos é farta a oferta de outros tipos de materiais. Rodrigues (2016) descreve depoimento de Marcel Anderson, 26 anos, trabalhador do local: "Aqui tem de tudo, desde comida até o cobre que a gente tira de ventilador, liquidificador e etc. O que nunca encontrei foi lixo de hospital, mas não acho difícil". Outro depoimento divulgado por Rodrigues (2016) é o de Célio Alves, 25 anos, também trabalhador local, mas que não veio da Cidade de Deus, bairro onde situa-se o aterro sanitário, ele relata ter acompanhado a migração na área e o aumento de concorrência, mas segundo o trabalhador: "Tem muito mais gente, mas não vejo problema, aqui tem lixo para todo mundo".

Ao lado da montanha de lixo, depositado sem qualquer controle, fiscalização ou proteção, cresce o número de "barracos" que em setembro de 2016 já somavam 60. Uma nova favela urbana está se formando com a migração dos trabalhadores da antiga favela Cidade de Deus, no local é possível ver até crianças trabalhando na coleta. Muito embora a falta de estrutura do local, os trabalhadores estão suprindo seu sustento. Rodrigues (2016) descreve outro trecho do depoimento de Marcel: "com o trabalho na área, ele diz que sustenta a esposa e mais cinco crianças do lixo reciclável que tira do local. Consegue lucrar, em média, $\mathrm{R} \$ 300$ por dia com o "laboratório" (uma espécie de tenda) que montou no meio do aterro, mas concorda com o fato de que corre riscos".

Diante dos relatos, percebe-se a situação de vulnerabilidade desse braço importante da cadeia produtiva do RSU reciclável. Esses trabalhadores contribuem com a preservação e manutenção do 
meio ambiente, que não se trata apenas de alocação e decomposição dos resíduos, mas de condições habitáveis da comunidade local atual, atribuem valor econômico ao RSU reciclável, transformam "lixo" em matéria prima e materializam a sua dignidade de ser humano. Todavia, para que essa dinâmica se consolide é preciso que outro braço da cadeia assuma seu papel dentro da comunidade. Santos (2000, p. 33) conclui que:

$\mathrm{Na}$ abordagem sistêmica, a percepção da sociedade na interpretação da realidade é vista a partir de uma complexa estrutura de relações entre o mundo interior e o mundo exterior dos indivíduos. Essa interpretação se dá a partir de um nível de consciência ligada aos significados e valores das diversas configurações ou totalidade dotadas de sentido. É a percepção da realidade que leva o indivíduo e a sociedade a se orientarem para as ações cotidianas e técnicas.

Os munícipes precisam saber e apreender a importância da sua participação, tanto para o meio ambiente, quanto para a comunidade como um todo.

\section{CONSIDERAÇÕES FINAIS}

Este estudo não esgota as possibilidades de práticas que possam intervir de forma sustentável na resolução dos resíduos sólidos urbanos recicláveis, mas busca compreender a dinâmica sistêmica da comunidade campo-grandense e disponibilizar informações que propiciem o desenvolvimento melhor adaptado a realidade do local.

Após a contextualização da problemática do tema proposto no decorrer da pesquisa, confirmou-se o potencial gerador de resíduo sólido urbano reciclável no município de Campo Grande-MS. Verificou-se que o município produz diariamente um volume considerável de resíduo, seja resíduo sólido comum, seja resíduo sólido reciclável. Todavia, a questão central da pesquisa assentou na dinâmica disfuncional sistêmica do ciclo produtivo do resíduo sólido urbano reciclável.

Para melhor compreender o panorama do RSU reciclável em Campo Grande, a pesquisa abrangeu três empresas locais, a SOLURB que é a concessionária responsável pela coleta do resíduo 
urbano, a REPRAM que comercializa os resíduos recicláveis e a Energisa que propõe um projeto de fomento ao descarte adequado dos resíduos sólidos urbanos recicláveis. Da observação da dinâmica dessas três empresas, constatou-se a existência de duas ferramentas importantes dentro do ciclo produtivo do RSU reciclável, a economia criativa e a logística reversa.

Não se descarta a existências de formas diversas de manipulação e destinação adequada do RSU reciclável, contudo, tanto a economia criativa quanto a logística reversa, já estão disponibilizadas no âmbito municipal. No que tange a logística reversa, esta apresenta-se na coleta seletiva que compreende quase todos os bairros do município, já a economia criativa é empregada no projeto Conta Cidadã.

Apesar de Campo Grande dispor de ferramentas importantes para a destinação adequada do RSU reciclável, estas não são devidamente aproveitadas e a pesquisa identificou como razão principal dessa estagnação o capital humano. Ora, se o município tem quantidade considerável de geração de RSU reciclável, se dispõe de empresas que coletam e comercializam o material e se existe um projeto socioambiental que estimula financeiramente $o$ comportamento ambientalmente adequado, a única justificativa é a humana. Claro que as políticas ambientais, sociais e econômicas disponibilizadas não estão completamente acabadas, entretanto, cumprem perfeitamente sua função ainda que em processo de adaptação.

A população precisa compreender e internalizar sobre a importância de cada ação individual que antes de ser isolada é apenas uma parte da motricidade coletiva. Este processo de apropriação e empoderamento social é gradativo, mas precisa de impulsionamento, alem da informação e educação ambiental, é preciso que as lideranças comunitárias sejam fortalecidas e estimuladas para que possam fomentar o rompimento de paradigma.

O desenvolvimento local, por intermédios de seus conceitos e práxis é competente para territorializar a comunidade no processo de desenvolvimento sustentável do ciclo produtivo do RSU reciclável. O empoderamento e a incorporação do capital humano na dinâmica sistêmica com o meio ambiente são um importante vetor da sinergia para o desenvolvimento de práxis inovadoras. Por 
fim, dada a complexidade e extensão da problemática sugere-se que outros pesquisadores retomem o assunto ora abordado para mais elucidações e profundidades.

\section{REFERÊNCIAS}

ABRELPE - Associação Brasileira de Empresas de Limpeza Pública e Resíduos Especiais. Panorama dos Resíduos Sólidos no Brasil. 2015.

BRASIL. MINISTÉRIO DA CULTURA. Plano da Secretaria de Economia Criativa: Políticas, diretrizes e ações 2011 a 2014, Brasília: Ministério da Cultura. 2012.

CASTELAR, Marina. Fim de lixão fecha comércios, deixa catadores na miséria e sem renda: Cerca de um terço dos 429 catadores estão desempregados. Campo Grande News: 2016 https://www.campograndenews.com.br/economia/fim-de-lixao-fecha-comercios-deixa-catadores-na-miseria-e-sem-renda Acessado em $\underline{11 / 10 / 2016}$.

COMPARATO, Fabio Konder. A civilização capitalista. São Paulo: Saraiva, 2013.

COSTA, Rogério H. da. O mito da desterritorialização: do "fim dos territórios" à multiterritorialidade. 3.ed. Rio de Janeiro: Bertrand Brasil, 2007.

LATOUCHE, Serge. EXISTIRÁ UMA VIDA APÓS O DESENVOLVIMENTO? Tradução de Maíra Albuquerque. Estudos de Sociologia, Revista do Programa de Pós-Graduação em Sociologia da UFPE, 2010, v. 16, n. 2, p. 217 - 230.

LIMA e MARQUES, Flávia e Antonio. Após inauguração, UTR vai reciclar 150 toneladas de material por dia. Campo Grande News: 2015. https://www.campograndenews.com.br/cidades/capital/apos-inauguracao-utr-vai-reciclar-150-toneladas-de-material-por-dia Acessado em 11/10/2016.

MARQUES, Heitor Romero. Desarollo local em la escala humana: uma exigência del siglo XXI. Campo Grande, MS: Mundial, 2013.

MARTENDAL, Anandra Gorges, SANTOS, Leomar dos. SIMPOI 2014, Anais. Contribuições da logística reversa para a sustentabilidade.

NASCIMENTO, Elimar Pinheiro do. Trajetória da sustentabilidade ambiental: do ambiental ao social, do social ao econômico. Estudos Avançados. 2012.

PEIXOTO FILHO, Getúlio Ezequiel da Costa; SANCHES DE OLIVEIRA, Paulo Tarso e COSTA DE OLIVEIRA, Abel. Reciclagem: benefícios e perdas obtidas em Campo Grande -MS. 240 Congresso Brasileiro de Engenharia Sanitária e Ambiental. 2007. Belo Horizonte-MG.

RODRIGUES, Luana. Com lixão fechado, catadores migram para aterro de entulhos da prefeitura. Campo Grande News: 2016. Disponível em: https://www.campograndenews.com.br/cidades/capital/com-lixao-fechado-catadores-migram-para-aterro-de-entulhos-da-prefeitura Acessado em 12/10/2016. 
RODRIGUES, Paulo Roberto Ambrosio. Introdução aos sistemas de transporte no Brasil e a logística internacional. São Paulo: Aduaneiras, 2000.

SANTOS, Aline. Metade de 13 toneladas diárias de recicláveis é enterrada como lixo. Campo Grande News: 2016 https://www.campograndenews.com.br/meio-ambiente/metade-de-13-toneladas-diarias-de-reciclaveis-e-enterrada-como-lixo Acesso em 11/10/2016.

SANTOS, Jacinta. Os caminhos do lixo em Campo Grande: disposição dos resíduos sólidos na organização do espaço urbano. Campo grande: UCDB, 2000.

SERRA, Neusa; FERNANDEZ, Rafael Saad. Economia Criativa: da discussão do conceito à formulação de políticas públicas. RAl - Revista de Administração e Inovação. São Paulo, v. 11, n. 4, p. 355-372, out/dez 2014.

TENÓRIO, Rildo de Oliveira. Estudo para aproveitamento energético de biogás de resíduos Sólidos urbanos em Campo Grande - MS. Dissertação (Mestrado em Eficiência Energética Sustentabilidade, na área de concentração de Biocombustíveis). UFMS, Campo Grande, 2015. 